\title{
Impact of Operational Definitions on the Predictors and Prevalence of Asthma Estimates: Experience from a University Students' Survey and Implications for Interpretation of Disease Burden
}

\author{
Olufemi O. Desalu ${ }^{*}$, Emmanuel O. Sanya ${ }^{1}$, Adekunle O Adeoti ${ }^{2}$, Sunday A \\ Aderibigbe $^{3}$, Philip M Kolo ${ }^{1}$
}

\section{OPEN ACCESS}

Citation: Desalu OO, Sanya EO, Adeoti AO, Aderibigbe SA, Kolo PM. Impact of Operational Definitions on The Predictors and Prevalence of Asthma Estimates: Experience from a University Students' Survey and Implications for Interpretation of Disease Burden. Ethiop J Sci.2018;28(6):725.

doi:http://dx.doi.org/10.4314/ejhs.v28i6.7

Received: February 22, 2018

Accepted: March 28, 2018

Published: November 1, 2018

Copyright: (C) 2018 Desalu OO., et al.

This is an open access article distributed under the terms of the Creative

Commons Attribution License, which permits unrestricted use, distribution, and reproduction in any medium, provided the original author and source are credited.

Funding: Investigators

Competing Interests: The authors declare that this manuscript was approved by all authors in its form and that no competing interest exists. Affiliation and Correspondence:

${ }^{1}$ Deparment of Medicine University of Ilorin Teaching Hospital Ilorin, Nigeria

${ }^{2}$ Department of Medicine, Ekiti State

University Teaching Hospital Ado-

Ekiti, Nigeria

${ }^{3}$ Department of Epidemiology and Community Health, University of Ilorin Teaching Hospital Ilorin, Nigeria

*Email: femuy1967@yahoo.co.uk
ABSTRACT

BACKGROUND: Inconsistent operational definitions during asthma surveillance can lead to inaccurate estimation of disease burden and formulation of health policy. This study aimed to evaluate the impact of different definitions on the prevalence estimates and predictors of asthma among university students in Ilorin, Nigeria. The secondary aim was to compare level of agreement of the different definitions.

METHODS: This cross-sectional study was carried out from June to August 2015. The European Community Respiratory Health Survey (ECRHS) questionnaire was self-administered by 1485 students. Asthma diagnosis was based on five definitions used in previous studies in the country. These were ECRHS, International Study of Asthma, Allergies in Childhood (ISAAC), Probable, Modified ECRHS and Modified Probable asthma definitions.

RESULTS: The prevalence rates varied from 10.4 to $24.1 \%$ depending on the definition. Prevalence obtained by using ECRHS definition significantly differed from estimates by other definitions ( $Z$ score $\geq 1.96 p<0.0001$ ) except modified probable asthma. Identified predictors of asthma varied from five to six depending on the definition, and their strength also differed by definition. Regardless of the definition, reported nasal allergy, skin allergy, family history of nasal allergy, asthma and parental smoking were the predictors of asthma. The Kappa statistics demonstrated a fair to almost perfect association between the ECRHS and other asthma definitions (Kappa $=0.334-0.841, p<0.001)$.

CONCLUSION: The prevalence rates and predictors of asthma are affected by operational definitions. Researchers need to adopt a uniform definition for accurate estimation of disease burden, international comparison of result and formulation of prevention policy.

KEYWORDS: Asthma definitions, Prevalence, Surveillance, Disease Burden, Health Policy 


\section{INTRODUCTION}

Asthma is one of the world's most common longterm medical conditions. The disease causes an estimated 250,000 deaths annually, and around 15 million disability-adjusted life years (DALYs) are lost annually through this disease (1-2). The burden of asthma in most regions of the world including developing countries have increased remarkably in recent years due to urbanization, industrialization, western lifestyle and increased awareness of the disease $(2,4)$. Previous epidemiological studies in different Nigerian populations have reported the prevalence range of $3 \%$ to $18.2 \%$ using different case definitions (513). These wide variations are attributed to study population, epidemiologic instrument and the lack of uniformity in the asthma definition. In clinical practice, evaluation of asthma applies a combination of history, physical examination and lung function test while less rigorous definitions mostly based on questionnaire history of symptoms and lung function are usually used for population-based studies (14-18). The operational definitions of asthma in recent epidemiological studies are inconsistent worldwide (19). The National Health and Nutrition Examination Survey (NHANES) has adopted uniform asthma definition for all ages in the USA (18). The European Community Respiratory Health Survey (ECRHS) and International study of asthma and allergies in childhood (ISAAC) (14-16) used a uniform definition to assess and compare the variation in the prevalence of asthma and risk factors. Unfortunately, there is no agreed consensus on epidemiological definition of asthma in adults in our setting; despite using similar survey instrument, the asthma definitions used in studies beyond childhood are inconsistent $(5,7,11,20)$. There are several advantages in studying asthma epidemiology using the same definitions; these include easy comparison with other studies; accurate estimation of the disease burden and formulation of appropriate prevention policies. Therefore, achieving precise estimates of the prevalence of asthma and risk factors are essential. We hypothesized that asthma definitions does not affect the prevalence estimates and burden in our study population. The study aimed to evaluate the impact of using different operational definitions on the predictors and prevalence of asthma estimates among University students in the middle belt, Nigeria. The secondary aim was to compare the level of agreement of these asthma definitions.

\section{METHODS}

Study design and setting: This was a crosssectional study carried out in three universities located in Ilorin, Middle Belt Nigeria. The first institution is a federal university with a student population of 34000 . The second institution is a private institution established by a religious organization with a student population of 4000, and the third one is established by the state government with a total population of 4820 . All the three universities are located within Ilorin, the state capital. The majority of the students reside within the community.

Sample size: We determined the minimum sample size using the Raosoft online sample calculator (21). The response distribution was $18.2 \%$ obtained from a previous study (11). The standard deviation is set at 1.96 for $95 \%$ confidence interval. The margin of error was \pm $2 \%$. The recommended sample size was 1384 . The design effect $=1.0$ because of the homogeneity of the students in participating institutions. Taking into account the expected response rate based on the pilot study, which was $85 \%$, and the minimum sample was increased to 1591 , a total of 1600 copies of the survey questionnaire were sent out.

Sampling technique: A multistage sampling technique with proportional allocation was used to select participating students. The total student population and the list of registered students in each department and their year of study were obtained from their respective academic offices. The faculty of study was the first sample frame containing the list of the faculties. In the second stage, a list of departments was the second sampling frame while the registered students formed the third sample frame. The trained interviewers selected students by simple random sampling from the list of registered students till

DOI: http://dx.doi.org/10.4314/ejhs.v28i6.7 
test. The null hypothesis (H0) was rejected if $\mathrm{Z}$ score $\geq 1.96$ or if $Z \leq-1.96$. Thereafter, we also calculated the agreement between ECRHS definition and 4 other definitions using the kappa estimate. Kappa indexes between 0.81 to 1.00 indicates a very good agreement, 0.61 to 0.80 represents substantial agreement, 0.41 to 0.60 means moderate agreement, 0.21 to 0.40 is interpreted as fair agreement and a value of less than 0.20 reflects a weak agreement between the definitions. Logistic regression analysis was performed to obtain the adjusted odds ratios (OR) and $95 \%$ confidence interval $(95 \% \mathrm{CI})$ to predict the risk of asthma. A $p$ value less than 0.05 was considered as statistically significant. The bar chart was generated for illustrating the sex distribution of the five asthma definitions.

Ethical approval: The study was conducted after receiving research approval from the Ethics and
Research Committee of the Kwara State Ministry of Health Ilorin, Nigeria.

\section{RESULTS}

General characteristics of the students: Out of the 1600 copies of the questionnaire that were distributed in the institutions, 1485 were fully completed and returned giving a response rate of $93.0 \%$ and constituting $3.5 \%$ of the overall student population of 42820 . There was no difference in mean age and gender of those excluded and the participants included the study. The only difference was in the year of study.

The mean age of the participating students was $20.9 \pm 3.1$ years. Seven hundred and eighty three were males $(52.7 \%)$ and $603(40.6 \%)$ were in their first year of study. A total of $386(26.0 \%)$ respondents reported a family history of allergic conditions, $51(3.4 \%)$ currently smoked tobacco at the time of the survey while $40(2.7 \%)$ reported parental smoking (Table 2).

Table 2: Characteristics of the participating students.

\begin{tabular}{|c|c|}
\hline Characteristics & n $(\%)$ \\
\hline Mean age (Mean \pm STD) & $20.9 \pm 3.1$ years \\
\hline \multicolumn{2}{|l|}{ Sex } \\
\hline Male & $783(52.7)$ \\
\hline Female & $702(47.3)$ \\
\hline \multicolumn{2}{|l|}{ Marital status } \\
\hline Single & $1440(97.0)$ \\
\hline Married/Divorced & $45(3.0)$ \\
\hline \multicolumn{2}{|l|}{ Year of study } \\
\hline $1-2$ & $1040(71.0)$ \\
\hline $3-\geq 4$ & $445(29.0)$ \\
\hline \multicolumn{2}{|l|}{ Family history of allergy } \\
\hline Yes & $386(26.0)$ \\
\hline No & $1099(74.0)$ \\
\hline \multicolumn{2}{|l|}{ Types of family allergy* } \\
\hline Asthma & $148(10)$ \\
\hline Nasal Allergy & $245(16.5)$ \\
\hline \multicolumn{2}{|l|}{ Tobacco smoking } \\
\hline Current smokers & $51(3.4)$ \\
\hline History of Parental smoking & $40(2.7)$ \\
\hline Total number of participants & 1485 \\
\hline \multicolumn{2}{|l|}{ *Multiple responses } \\
\hline $\begin{array}{l}\text { Prevalence of respiratory symptoms and use of } \\
\text { asthma medications: The prevalence of }\end{array}$ & $\begin{array}{l}\text { nocturnal cough was } 21.4 \%(95 \% \text { CI: } 19.3- \\
23.7 \%) \text {; it was the most common asthma }\end{array}$ \\
\hline
\end{tabular}

DOI: http://dx.doi.org/10.4314/ejhs.v28i6.7 
symptom followed by nocturnal shortness of breath was $13.5 \%(95 \% \mathrm{CI}: 11.6-15.4 \%)$ and chest tightness was $12.8 \%$ (95\% CI: 11.1-14.5\%). Also, 9.5\% (95\% CI: 7.9-11.1\%) had diagnosed current asthma (an asthma attack in past 12 months and currently uses asthma medication).

Prevalence of asthma using the different definitions: The prevalence estimate varied from 10.4 to $24.1 \%$ depending on the definition. The prevalence of asthma using ECRHS, modified ECRHS and ISAAC definition were 18.7\% (95\% CI: $16.7-20.7 \%$ ) , 24.1\% (95\% CI: $22.0-26.5 \%)$, 12.1\% (95\% CI: $10.5-13.9 \%)$ respectively. The prevalence of asthma using the definition of probable asthma and modified definition of probable asthma were respectively $10.4 \%(95 \%$ CI: $9.0-12.1 \%$ ) and $16.9 \%$ (95\% CI: $15.0-18.9 \%$ ). All the definition for prevalence of asthma reported more asthma occurrence in the females than in the male subjects (Figure 1). On stratified analysis of the study sites, there was no significant difference in the prevalence of asthma among the universities using any of the five definitions: ECRHS $(\chi 2=1.54 \mathrm{df}=2 \quad \mathrm{p}=0.462)$, modified ECRHS $(\chi 2=1.40 \quad \mathrm{df}=2 \quad \mathrm{p}=0.498)$, $\operatorname{ISAAC}(\chi 2=3.19 \mathrm{df}=2 \quad \mathrm{p}=0.203), \quad$ probable $\operatorname{asthma}(\chi 2=0.462 \quad \mathrm{df}=2 \mathrm{p}=0.794)$ and modified probable asthma $(\chi 2=4.10 \mathrm{df}=2 \mathrm{p}=0.129)$.
- Total, ECRHS

definition, $18.7 \%$

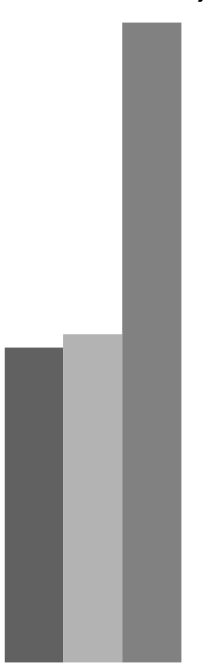

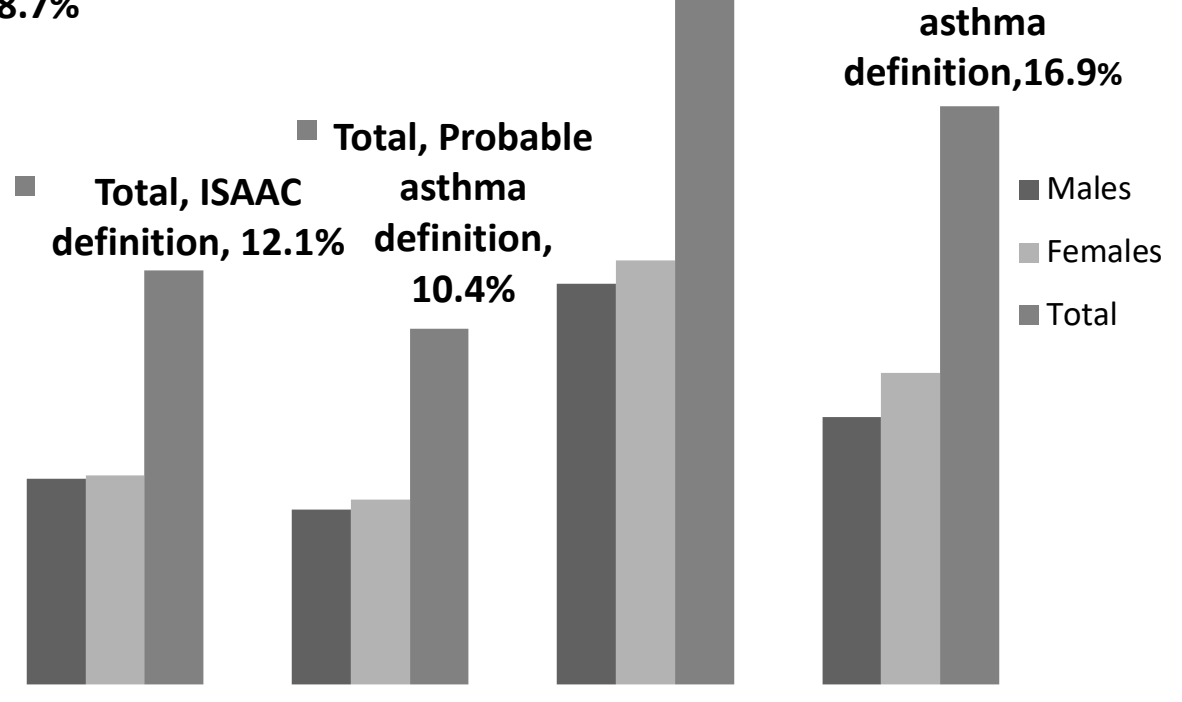

\section{Total Modified ECRHS \\ definition, $24.1 \%$}

Asthma definitions

Figure 1: Sex distribution by different asthma definition

Comparison of the different estimates of asthma prevalence: A two-proportion $\mathrm{z}$ scoretest was performed to determine whether there was a significant difference between the prevalence estimates obtained. There were statistically significant differences between the

DOI: http://dx.doi.org/10.4314/ejhs.v28i6.7 
asthma estimates by ECRHS and three other definitions: probable asthma modified ECRHS and ISAAC used in this study $(\mathrm{Z}$ score $\geq 1.96$ $\mathrm{p}<0.0001)$ with the exception of modified probable asthma (Table 3).

Table 3: Comparison of the difference estimates of asthma prevalence.

\begin{tabular}{llllll}
\hline $\begin{array}{l}\text { ECRHS } \\
\%(95 \% \mathrm{CI})\end{array}$ & \multicolumn{1}{c}{$\begin{array}{c}\text { Other definitions } \\
\%(95 \% \mathrm{CI})\end{array}$} & $\begin{array}{l}\text { Differenc } \\
\mathrm{e}\end{array}$ & $\mathrm{Z}$ score & $p$ value & Interpretation \\
\hline & $\begin{array}{l}\text { ISACC } \\
12.1 \%(10.5-13.9 \%)\end{array}$ & 0.066 & 5 & $<0.0001$ & $\begin{array}{l}\text { Significant } \\
\text { difference }\end{array}$ \\
\hline $\begin{array}{l}\text { Probable asthma } \\
10.4 \%(9.0-12.1 \%) \\
\text { Modified ECRHS }\end{array}$ & 0.083 & 6.4 & $<0.0001$ & $\begin{array}{l}\text { Significant } \\
\text { difference }\end{array}$ \\
& $\begin{array}{l}24.1 \%(22.0-26.5 \%) \\
\text { Modified probable } \\
16.9 \%(15.0-18.9 \%) .\end{array}$ & 0.018 & 1.3 & 0.0003 & $\begin{array}{l}\text { Significant } \\
\text { difference }\end{array}$ \\
& & & 0.1998 & $\begin{array}{l}\text { No Significant } \\
\text { difference }\end{array}$ \\
\hline
\end{tabular}

Degree of agreement and Diagnostic Performance of definitions: The Kappa statistics demonstrated a fair to almost perfect between the definitions (Kappa $=0.334-0.841, \mathrm{p}<0.001$ ), where the modified ECRHS revealed the highest concordance with the ECRHS definition (kappa = $0.841, \mathrm{p}<0.001)($ Table 4).

Table 4: The agreement between the definition and the ECRHS definition

\begin{tabular}{lllll}
\hline Operational definitions I & Operational definitions II & Kappa & P values & Agreement \\
\hline \multirow{2}{*}{ ECRHS } & ISACC & 0.334 & $<0.0001$ & Fair \\
& & & & \\
& Probable asthma & 0.581 & $<0.0001$ & Moderate \\
& Modified ECRHS & 0.841 & $<0.0001$ & Almost Perfect \\
& Modified probable & 0.639 & $<0.0001$ & Substantial \\
& asthma & & & \\
\hline
\end{tabular}

Impact of operational definitions on identified risk factor for asthma: Five risk factors for asthma were identified respectively using ECRHS, ISAAC, Probable asthma and modified ECRHS asthma case definition; these were self reported nasal allergy, skin allergy, family history of nasal allergy and asthma and parental smoking. Six risk factors for asthma were identified using the definition of probable asthma, these were female sex, self-reported nasal allergy, skin allergy, family history of nasal allergy and asthma and parental smoking. The ECRHS, modified ECRHS and modified probable asthma identified family history of asthma aOR $=3.34(95$ CI 2.205.06), 2.91(95CI 1.13-4.35) and 3.37(95CI 2.115.49) respectively as the strongest predictor. The ISAAC and probable asthma definition as a dependent variable, identified parental smoking $\mathrm{aOR}=3.42$ (95 CI 1.55-7.51) and 3.94(95 CI 1.679.27) respectively as the strongest predictor of asthma (Table 5). 
Table 5: Predictors of asthma using the different asthma definitions.

\begin{tabular}{|c|c|c|c|c|c|}
\hline Predictors & $\begin{array}{l}\text { ECRHS } \\
\mathrm{aOR}(95 \mathrm{CI})\end{array}$ & ISAAC aOR(95CI) & $\begin{array}{l}\text { Probable asthma } \\
\text { aOR }(95 \mathrm{CI})\end{array}$ & $\begin{array}{l}\text { Modified ECRHS } \\
\text { aOR(95CI) }\end{array}$ & $\begin{array}{l}\text { Modified probable } \\
\text { aOR(95CI) }\end{array}$ \\
\hline Age & $0.97(0.92-1.01)$ & $0.98(0.93-1.04)$ & $0.98(0.92-1.04)$ & $0.98(0.94-1.02)$ & $0.97(0.93-1.02)$ \\
\hline Female Sex & $1.23(0.91-1.67)$ & $1.23(0.87-1.72)$ & $1.27(0.87-1.86)$ & $1.26(0.96-1.64)$ & $1.40(1.03-1.91)$ \\
\hline $\begin{array}{l}\text { History of Nasal } \\
\text { allergy }\end{array}$ & $2.76(2.02-3.78)$ & $2.56(1.79-3.66)$ & $3.13(2.11-4.65)$ & $2.71(2.04-3.60)$ & $3.74(2.72-5.16)$ \\
\hline $\begin{array}{l}\text { History of skin } \\
\text { allergy }\end{array}$ & $2.58(1.77-3.76)$ & $1.70(1.11-2.60)$ & $2.62(1.70-4.06)$ & $2.14(1.49-3.07)$ & $1.80(1.22-2.66)$ \\
\hline $\begin{array}{l}\text { Family history of } \\
\text { skin allergy }\end{array}$ & $1.09(0.72-1.66)$ & $0.92(0.57-1.48)$ & $0.97(0.59-1.59)$ & $1.14(0.77-1.69)$ & $1.36(0.89-2.06)$ \\
\hline $\begin{array}{l}\text { Family of nasal } \\
\text { allergy }\end{array}$ & $1.99(1.37-2.89)$ & $1.63(1.06-2.49)$ & $2.30(1.48-3.58)$ & $1.72(1.21-2.46)$ & $1.62(1.01-2.37)$ \\
\hline $\begin{array}{l}\text { Family history of } \\
\text { asthma }\end{array}$ & $3.34(2.20-5.06)$ & $1.84(1.15-2.94)$ & $3.37(2.11-5.38)$ & $2.91(1.13-4.35)$ & $3.37(2.11-5.49)$ \\
\hline Parental smoking & $2.62(1$ & 3.42 & $3.94(1.67-9.27)$ & $8-5.43)$ & $2.59(1.14-5.88)$ \\
\hline Cigarette smoking & $1.61(0.77-3.36)$ & $1.66(0.78-3.54)$ & $0.80(0.32-1.98)$ & $1.68(0.84-3.37)$ & $0.82(0.37-1.83)$ \\
\hline
\end{tabular}

Data presented as adjusted odd ratio with $95 \%$ Confidence Interval

Model adjusted for age, sex, history of reported nasal allergy, skin allergy, and family history of skin allergy, nasal allergy, and asthma. parental smoking and active tobacco smoking

\section{DISCUSSION}

The main findings of this study show that the prevalence estimate varied from 10.4 to $24.1 \%$ depending on the definition used. The prevalence estimate by ECRHS definition differs significantly from the three other definitions. One asthma definition identified six risk factors of asthma while the others identified five. Reported nasal allergy, skin allergy, family history of nasal allergy and asthma and parental smoking were the predictors of asthma regardless of the definition. The modified ECRHS had the highest concordance with the ECRHS definition (kappa = $0.841, \mathrm{p}<0.001)$. It has been reported that the prevalence estimate and disease burden are determined by adopted asthma definition (22-24). This was clearly observed in this study where there was a statistically significant difference and a wide variation in asthma prevalence estimates using the five sets of diagnostic criteria. The lowest estimate was $10.4 \%$ by ISAAC definition of asthma and the highest estimate was $24.1 \%$ by modified ECRHS. The reason for this variation was their difference sensitivity as a diagnostic tool. The prevalence of asthma using the ECRHS definition in this study was $18.7 \%$. This is in tandem with $18.2 \%$ reported by Erhabor et al in
Southwestern Nigeria. This closeness may be as result of the substantial agreement between ECRHS and modified ECRHS( kappa $=0.841$ ). However, our values was higher than 14.1-16.4\% determined in previous studies among students in Nigeria (6,7,20). All these previous studies lack uniformity in asthma definition despite having almost similar survey instruments. Currently, the available asthma definitions have their pros and cons, and there is no gold standard definition of asthma because of its heterogeneity and many phenotypes (25-27). In this regard, the lack of a widespread and accepted operational definition of asthma beyond childhood may lead to a potential problem of international comparison, under or over-diagnosis, inaccurate estimation of burden and healthcare resource planning.

This study also found that irrespective of asthma case definition, asthma was more frequent in female than in male subjects, although not statistically significant. It is due to smaller airway calibre size and higher bronchial reactivity in females (28). Apart from nasal allergy, nocturnal cough was the most common reported symptom, and this is in agreement with what was reported in previous studies $(6,11)$.

In this study, there was a slight variation in number and strength of identified predictors of

DOI: http://dx.doi.org/10.4314/ejhs.v28i6.7 
asthma by different asthma definitions (6 vs. 5). The independent predictors of asthma in this study are similar to what was reported in a previous study in locality ten years ago (29). Another important finding is the association of parental smoking with asthma in this study; those who reported parental smoking were three to four times likely to be associated with diagnosis of asthma. This is in agreement with other studies that observed a clear association between parental smoking and asthma or wheezing (30-32). The findings might prompt a future case-control and longitudinal study which will allow in depth exploration and analysis of impact of environmental tobacco smoking before a generalisation and causal inference can be made.

Asthma defined by ECRHS, modified ECRHS and modified probable asthma definition identified family history of asthma as the strongest predictor, aOR $=3.34$ (95 CI 2.20-5.06), 2.91(95 CI 1.13-4.35) and 3.37(95 CI 2.11-5.49) respectively. In contrast, asthma defined by ISAAC and probable asthma definition identified parental smoking aOR=3.42(95 CI 1.55-7.51) and 3.94(95 CI 1.67-9.27) as the strongest predictor of asthma. This study also noted that estimated odd ratios were larger for the probable asthma definition than the other definitions of asthma. This is due to very high specificity of definition of probable asthma when compared to other definitions. The probable asthma requires three or more positive answers to questions on symptoms of asthma, which strengthened the associations with the risk factors and also increased the estimated specificity and positive predictive value (PPV) of the definition. The PPV is a function of true prevalence of a disease, specificity and sensitivity (33-34).

This study was able to assess the impact of the operational definitions on the prevalence of asthma estimate in a younger population that has a lesser risk of misclassification of the disease. The confounding effect of language on the reporting of symptoms was minimized in our study by using a self-administered and standardized questionnaire written in the language of instruction which was well understood by the participants. This study was a cross-sectional design. Therefore, a causal relationship cannot be established between identified predictors and asthma. Also, the data on parental smoking was self- reported with no objective measurement of exposure to smoking like measurement of nicotine level. The questionnaire estimation is controversial because it underestimates the level of exposure. Some studies have reported a good correlation between smoking evaluated by questionnaire and serum cotinine levels (35).

In conclusion, this study has shown that the prevalence and risk factors for asthma are affected by operational definitions. There is a need for epidemiologist and researchers to adopt a uniform definition with good performance for accurate determination of disease burden, international comparison and formulation of effective prevention and disease control policy.

\section{ACKNOWLEDGEMENTS}

We acknowledge the support of the postgraduate residents in the Department of Medicine that provided logistic support and supervision of field workers during the data collection.

\section{REFERENCES}

1. Masoli M, Fabian D, Holt S, Beasley R. The global burden of asthma: executive summary of the GINA Dissemination Committee report. Allergy, 2004; 59(5):469-78.

2. The Global Asthma Report 2014.Auckland, New Zealand: Global Asthma Network, 2014. available at http://www.globalasthma report ,org/reseources/Global_Asthma_Rep ort 2014.pdf Accessed June 19, 2016

3. Falade AG, Ige OM, Yusuf BO, Onadeko MO, Onadeko BO. Trends in the prevalence and severity of symptoms of asthma, allergic rhinoconjunctivitis, and atopic eczema. $J$ Natl Med Assoc, 2009; 101: 414-18.

4. Masoli M, Fabian D, Holt S, Beasley R. Global Burden of Asthma. 2004. Available: http://ginasthma.com/ReportItem.asp? $11=2 \& 12=2 \& \operatorname{int} I d=95$. date last accessed 19 October 2012

5. Desalu OO, Oluboyo PO, Salami AK. The prevalence of bronchial asthma among adults 
in Ilorin, Nigeria. African Journal of Medicine and Medical Sciences, 2009; 38(2):149-154.

6. Erhabor GE, Agbroko SO, Bamgboye P, Awopeju OF. Prevalence of asthma symptoms among university students 15-35 years of age in Obafemi Awolowo University Ile-Ife Osun State. Journal of Asthma, 2006; 43(2):161-4.

7. Ibeh CC, Ele PU. Prevalence of bronchial asthma in adolescent in Anambra State, Nigeria. Nigerian Journal of Internal, Medicine, 2002; 5:23-6.

8. Faniran AO, Peak JK, Woolcock AJ. Prevalence of atopy, asthma symptoms and diagnosis and the management of asthma: comparison of an affluent and non-affluent country. Thorax, 1999; 54(7):606-610.

9. Falade AG, Olawuyi JF, Osinusi K, Onadeko BO. Prevalence and severity of symptoms of asthma, allergic rhino-conjunctivitis and atopic eczema in secondary school children in Ibadan Nigeria. East Afr Med J, 1998; 75(12):695-8.

10. Falade AG, Olawuji JF, Osinusi K, Onadeko BO. Prevalence and severity of symptoms of asthma, allergic rhinoconjunctivitis, and atopic eczema in 6 to 7 -yearold Nigerian primary school children: The international Study of Asthma and Allergies in Childhood. Med Princ Pract, 2004; 13: 20-5.

11. Erhabor GE, Obaseki DO, Awopeju OF, Ijadunola KT, Adewole OO. Asthma in auniversity campus: a survey of students and staff of Obafemi Awolowo University,Ile-Ife, Nigeria. J Asthma, 2015; 27:1-7.

12. Adetoun MB, Briggs DJ, Hansell AL. Prevalence of asthma and respiratory symptoms in children in a low socioeconomic status area of Nigeria. Int $J$ Tuberc Lung Dis. 2013 ; 17(7):982-8.

13. Obaseki DO, Awoniyi FO, Awopeju OF, Erhabor GE. Low prevalence of asthma in Sub-Saharan Africa: a cross-sectional community survey in a suburban Nigerian town. Respir Med, 2014; 108(11):1581-8.

14. European Community Respiratory Health Survey. Variations in the prevalence ofrespiratory symptoms, self-reported asthma attacks, and use of asthma medications in the European Community Respiratory Health Survey (ECRHS). Eur Respir J, 1996;9:687.

15. Janson C, Chinn S, Jarvis D, Burney PG. Physician-diagnosed asthma and drug utilization in the European Community Respiratory Health Survey Eur Respir J, 1997;10:1795-1802DOI:10.1183/09031936. 97.10081795.

16. Janson C, Anto J, Burney $\mathrm{P}$ et al. The European Community Respiratory Health Survey: what are the main results so far? Eur Respir J, 2001; 18: 598-611.

17. Asher MI, Keil U, Anderson $\mathrm{HR}$ et al: International Study of Asthma and Allergies in Childhood (ISAAC): rationale and methods. Eur Respir J, 1995, 8:483-91.

18. Akinbami LJ, Moorman JE, Bailey et al. Trends in asthma prevalence, health care use, and mortality in the United States, 20012010. NCHS data brief, no 94. Hyattsville, MD: National Center for Health Statistics. 2012

19. Sá-Sousa A, Jacinto T, Azevedo LF et al. Operational definitions of asthma in recent epidemiological studies are inconsistent. Clin Transl Allergy, 2014 4; 4:24.Doi:10.1186/ 2045-7022-4-24.

20. Akanbi MO, Ozoh OB, Akanbi FO, Ukoli CO. Self-reported asthma symptoms among adults aged 20-30 years in a Nigerian university: a cross-sectional study. High Med Res $J, 2013$; 13:8-11

21. Raosoft Incorporation: Raosoft Sample Size Online Calculator. (Internet) c2004 (cited 2017 March 15). Available from: http://www.raosoft.com/samplesize.html

22. Burney P GJ, Laitinen L A, Perdrize S et al. Validity and repeatability of the IUATLD bronchial symptoms questionnaire: an international comparison. Eur Respir J, 1989; 2: 940.

23. Van Wonderen KE, Van Der Mark LB et al: Different definitions in childhood asthma: how dependable is the dependent variable? Eur Respir J, 2010, 36:48-56. 
24. Beasley R. Worldwide variation in prevalence of symptoms of asthma, allergic rhinoconjunctivitis, and atopic eczema: ISAAC. Lancet, 1998; 351: 1225-32

25. European Community Respiratory Health Survey: Symptom outcome measures in the ECRHS.http://www.ecrhs.org/Publications /symptomoutcomes.pdf

26. Pekkanen J, Pearce N: Defining asthma in epidemiological studies. Eur Respir J, 1999, 14:951-7.

27. Pekkanen J, Sunyer J, Anto JM, Burney P: Operational definitions of asthma in studies on its aetiology. Eur Respir J, 2005, 26:2835.

28. Britton J, Pavord I, Richards K et al. Factors influencing the occurrence of airway hyperreactivity in the general population: the importance of atopy and airway calibre. Eur. Respir. J, 1994;7:881-7

29. Desalu OO, Salami AK, Oluboyo PO. SelfReported Risk Factors of Asthma in a Nigerian Adult Population. Tur Toraks Der, 2009; 10:56-62.

30. Gupta D, Aggarwal AN, Chaudhry K et al. Household environmental tobacco smoke exposure, respiratory symptoms and asthma in non-smoker adults: a multicentric population study from India. Indian $J$ Chest Dis Allied Sci, 2006; 48(1):31-6.

31. Gonzalez-Barcala FJ, Pertega $\mathrm{S}$ et al. Impact of parental smoking on childhood asthma. $J$ Pediatr (Rio J), 2013;89:294-9.

32. De Sario M, Forastiere F, Viegi G et al. Parental smoking and respiratory disorders in childhood. Epidemiol Prev 2005 ;29 : 52-6

33. Brenner $\mathrm{H}$, Gefeller $\mathrm{O}$. Use of positive predictive value to correct for disease misclassification in epidemiological studies. Am J Epidemiol, 1993; 138: 1007-15

34. Green MS. Use of predictive value to adjust relative risk estimates biased by misclassification of outcome status. Am J Epidemiol, 1983; 117: 98-105.

35. U. Gehring, B.P. Leaderer, J. Heinrich, M. Oldenwening, M.E. Giovannangelo, E. Nordling, et al.Comparison of parental reports of smoking and residential air nicotine concentrations in children Occup Environ Med, 2006; 63:766-72. 